\title{
Use of personal protective equipment during the COVID-19 epidemic in nursing homes - a students' perspective
}

\author{
Adriana Kozina', Jožica Čehovin Zajc², Marija Milavec Kapun \\ 'University of Ljubljana, Faculty of Health Sciences, Ljubljana, Slovenia \\ 2 University of Ljubljana, Faculty of Social Sciences, Ljubljana, Slovenia \\ E-mail: adri.kozina@gmail.com; jozica.cehovin-zaj@@fdv.uni-lj.si; marija.milavec@zf.uni-lj.si
}

\begin{abstract}
Introduction: Spreading of the new coronavirus among the community after spring 2020 considerably impacted the lives of residents and the work of staff in Slovenia's nursing homes. Infections were detected in $99 \%$ of all nursing homes, with their residents accounting for $58 \%$ of deaths due to COVID-19 in 2020. Even before the epidemic, nursing homes were understaffed - the epidemic exacerbated this problem (more work with strict protective measures and less staff due to illness). Those who were still working also faced a bigger workload following the introduction of many additional preventive measures. Consistent and proper use of personal protective equipment is vital for managing infections and keeping residents and staff healthy, which may prove challenging for them both. The use of personal protective equipment and implementation of measures to limit the spread of the virus also seriously constrains residents' ability to socialise. The aim of this paper is to explore the challenges and issues encountered by residents, staff and students in nursing homes while using personal protective equipment and implementing other measures to limit the spread of infection. Methods: In spring 2021, in-depth interviews were conducted with ten nursing and medical students who had worked or were working in nursing homes as part of 'Covid expeditions'. The interviews were transcribed and then coded using NVivo software. Content analysis was performed and key findings were supported with interviewee quotes. Results: Students found the nursing home staff and residents have faced several challenges in combating COVID-19. They identified the lack of resources and information, the organisational and psychological burdens on staff, the social isolation and the lack of personal contact with caregivers as the biggest problems for residents. Discussion: While personal protective equipment use and the application of other measures to limit the spread of the virus is very important to prevent the
\end{abstract}


transfer of diseases such as COVID-19, if their implementation is to be effective, conditions like sufficient resources, adequate organisation and guidelines, enough staff knowledge and the consistent use of appropriate personal protective equipment must be ensured. It is important to consider the importance of the residents' social life and and prevent excessive social isolation. Conclusions: To effectively control diseases like COVID-19, it is necessary to study the problems that arise in such situations among the staff and residents of nursing homes, especially those occurring while implementing infection-prevention measures and using personal protective equipment so as to help manage similar situations in the future. Our findings may serve as a basis for both recommendations for better and safer working and living in these facilities for staff and residents alike and for future research in this field.

Keywords: Coronavirus, problems, elderly, Covid expedition, social welfare institutions

\section{Introduction}

In 2020, COVID-19 had a major impact on life and work in nursing homes in Slovenia. Most (58\%) deaths in Slovenia due to COVID-19 in that year were among nursing home residents (UKOM, 2020). By November 2020, more than $85 \%$ of nursing homes had already experienced a coronavirus outbreak.

Nursing homes across the country already faced staff shortages before the epidemic, with the problem then only worsening (Zbornica-Zveza, 2020). The staff had to use considerable amounts of personal protective equipment (PPE) (NIJZ, 2020), which requires great consistency at work and is physically demanding. They also had to implement many other measures to prevent/limit the spread of the virus, overall creating more difficulties for both them and the residents (White et al., 2021).

Some research has already shown that PPE and measures to contain the coronavirus such as physical distancing, respiratory hygiene etc. play a key role in fighting diseases like COVID-19, given that transmission is largely airborne (Lotfi et al., 2020). We must consider many factors that affect virus infection prevention/control to spare problems for staff and to avoid errors by them. Some have already been highlighted by researchers around the world (Szczerbinska, 2020; Thompson et al., 2020), such as sufficient staff resources with appropriate knowledge, appropriate building design, precise work guidelines, adequate and quality material resources, and plans for residents' safe social contacts. The importance of healthcare workers' perception and knowledge about COVID-19 for better outcomes has also been noted (Bhagavathula et al., 2020).

Not much research can be found on the challenges staff and residents of nursing homes have faced during the COVID-19 epidemic. Therefore, the aim of our study was to examine the issues encountered by residents, staff and students in nursing homes while using PPE and applying other measures to lim- 
it the spread of the virus. The research question is: which kinds of problems did the students observe in Slovenia's nursing homes among the staff and residents arising from PPE use and the other measures to limit the virus' spread with a focus on resources, staff knowledge, consistent use of PPE and associated errors.

\section{Methods}

In spring 2021, we conducted in-depth interviews with ten nursing and medical students who had worked during the first wave and/or were working during the second wave of the epidemic across Slovenia as part of 'Covid expeditions' in nursing homes, places most impacted by the epidemic. The coronavirus situation meant the interviews were performed using the Zoom interface. Interviews were recorded, transcribed and then coded in NVivo.

Content analysis was carried out to answer the research question. Students were asked to describe issues arising at work they had noticed among the students, staff and residents in nursing homes while implementing measures to limit the virus' spread and using PPE. We asked them about material shortages, organisational problems and epidemic-related situations in the nursing homes where they were working. We asked them how they assessed the knowledge of staff and consistency in PPE use.

We summarised the main themes and supported the key findings with quotes from the interviewees and translated them into English. Students labelled with numbers $1-5$ had worked in nursing homes during the first wave, while students labelled 6-10 had done so during the second wave of the COVID-19 epidemic.

\section{Results}

We coded the text and designed the themes. The focus of analysis followed the aim of our research by considering the observed availability of resources (staff and PPE), knowledge and consistency of PPE use by staff, errors made while using PPE and implementing preventive measures to limit the spread of the coronavirus, and the problems encountered by residents during the epidemic.

\section{Staff shortage and exhaustion}

Almost all the students who had worked in both waves reported staff shortages: "In terms of staff, there was a general shortage anyway" (S2), and an increase in staff working hours: "They have been working to such a schedule for a very long time. Regardless of weekends, holidays. 12 hours, 12 hours..." (S1). It is also more difficult to work while using a lot of PPE.

Consequently, staff shortages and work overload create difficulties for the implementation of virus control measures: "There was supposed to be a team of people, who were meant to work only in the red zone and the rest, who were 
supposed to work in the grey zone, but it all got mixed up because there was a staff shortage" (S4).

The staff's mental and physical exhaustion was also reported to a large extent during both waves: "Exhaustion, depression" (S7).

\section{The availability and quality of PPE}

Differences between the results for the first and second waves mean that this set of data is divided into two parts.

First wave: In contrast to mass media reports, students generally reported a sufficient level of PPE: "Basically, we were not missing anything" ( $\left.\mathrm{S}_{1}\right)$.

Still, some students also reported a lack of PPE and the dangerous consequences of reusing it. If PPE items are stored for later reuse, undisinfected areas pose a risk when staff collect the PPE again. There is also a greater risk of contamination when clothing is reworn.

I think the biggest problem was PPE. We had it, but we were a little more frugal. We saved these coats when we went to lunch. We took them off, didn't throw them away, and then we put them back on again, and there was a risk of becoming infected. $\left(\mathrm{S}_{5}\right)$

In some nursing homes, the staff did not have Tyvek (i.e. a disposable, highly protective coat) to use for their protection, even while working in the red zone.

Q: So, you were working in the red zone, and you didn't have a Tyvek?

A: No, no. We had that blue coat, with a rubber band on the sleeves. I know they already had those 'space suits' at the end, but in testing they found out that they were leaky, so we didn't use them, they said it didn't make sense. $\left(\mathrm{S}_{2}\right)$

Second wave: Students had varied experiences regarding the availability of PPE and its quality. Mostly sufficient quantities were reported, but poorer quality. This could pose a risk of infection transmission to both staff and residents. PPE that tears and is made of poor material can create a bigger transmission risk because staff are wearing deficient protection. Awareness of the equipment's weaknesses also affects the mental state of the staff because they do not feel safe at work.

Umm, the material was there, but it was bad. The gloves I swear, every other one did... I said... This will be filmed now, but if condoms were like this, population growth would be $100 \%$. They were old, it was a batch of bad gloves, just porous. And we used washable coats. Washable coats!!! (Sg). 


\section{Knowledge and consistency among employees regarding PPE use}

In both waves, most students reported that the staff did not possess adequate knowledge about PPE use and did not use it consistently. Among the main reasons for this inconsistency, about half of them saw staff ignorance as $S$ the biggest problem: Q: "What was the biggest problem with PPE in the nursing home you were working at" A: "Careless wearing" $\left(\mathrm{S}_{4}\right)$, and a lack of knowledge: "Very, very poorly trained staff, including the management" (S9).

Just one student reported organised training for staff on proper PPE use. He also positively assessed the staff's knowledge: “They had these trainings, they came to them, and they refreshed their knowledge; I think they were just familiar with PPE" (S10).

The students also noted the lack of clear guidelines on PPE use and implementation of the measures for containing the virus.

It has been said for a while that we have nitrile gloves up and ones over, you treat the lower ones as your skin and disinfect them, and you change the upper ones. Then they said: 'It's better if you have two layers and you put both up and down'. Then they said: 'It makes no sense at all to use two layers'. I am unsure which is correct. I didn't quite understand that. Obviously, it's not that important if the guidelines change so often. (S2)

They also missed checks on compliance with the measures and proper PPE use.

No (i.e. no checking), due to exhaustion, I think the checking has also dropped. There was too much to do. So, if I had decided not to wear the vizor, no one would have said anything to me. Even if I said that I would only wear a Tyvek without a mask and a vizor, no one would say anything. (S5)

The second set of reasons for inconsistent PPE use and implementation of other measures to limit the coronavirus involved fatigue and tiredness: "There was a lot of equipment but, due to exhaustion, they did not wear it" ( $\left.\mathrm{S}_{4}\right)$.

Finally, an underestimation of the seriousness of the situation was also noted among the staff along with a false sense of security due to overcoming the disease: "But she, because she got over it ( COVID-19), she said: 'I think I'm good, I'm over, I don't need a mask and a vizor"' (S7).

Only one student reported organised checking and therefore greater staff consistency: "Yes, in the first nursing home, we twice had a check. Q: Do you think this has improved the consistency in the use of PPE? A: Yeah, basically it has, yeah" (S10). 


\section{Most common mistakes with PPE use}

The students noticed quite a few mistakes at work that should be pointed out and prevented in the future. In most nursing homes, staff saved for reuse the same protective coats during lunch. The coats made contact with different surfaces (chairs, tables etc.) and, after grabbing them again, they did not disinfect those surfaces. Such a surface (fomite), poses a risk for transmission of the virus.

In the ward, we took it off (the coat), like everyone, with or without disinfection, we usually left it on a chair in the dining room and went up stairs to the main dining room without it. Later, we put the coat back on, as well as the hat and vizor we had worn before. This could be better. Q: Did you later disinfect the chair? A: No.(S4)

Students also observed that the staff often did not follow the correct wiping techniques and took faster, more dangerous shortcuts.

It seems to me, that the biggest mistake came when taking off the coats that we had to constantly put on and off, and the employees didn't care to touch them where it was clean, they took them off with their bare hands, they just placed them down, and would then disinfect their hands a little bit.

Unclear guidelines meant that the use of gloves varied. In some places, staff wore single gloves, which they changed, and then they disinfected their hands, which is supposed to be the correct way. Others wore double or even triple gloves and changed only the top layer. Such gloves become permeable and carry the risk of infection transmission, while it is also impossible to disinfect one's hands regularly. Errors were observed in the exchange of disposable PVC coats between patients and in some nursing homes, even the complete absence of them: "But sometimes they didn't have any at all. They thought: 'Tyvek is protection anyway'; But it is protection for you, and you can still transmit!" (S10).

It was similar regarding equipment like a trolley and dry bath foam. These were intended for the whole department and were not disinfected between use by different residents.

The mixing of staff from different zones was observed. This may create the possibility of infection transmission and should thus be avoided. Many errors were observed during the time for resting and meals - inconsistent adherence to safety distance, non-use of PPE, many people in a small space, the lack of ventilation.

They had lunch and coffee together, not separately. The nurses were eating together, talking without masks. So I think those who were infected got it from other staff, not from the residents. I was there, I had 
a mask, and they used to say: 'come on, you will have coffee, take this mask off sometime' (S9).

In one case, it was also observed that asymptomatically infected staff were still working: "At the end, the whole house got infected, everyone was infected, all of the staff, people were working who were infected, asymptomatic and symptomatic, as it seemed to someone to be working" (S9).

The same student also noticed the worrying careless attitude of those in charge: "Because to say: yes, the best way is that everyone gets infected and then it will get better. You can't say that, speaking about people aged 80 and more!" (S9).

\section{PPE use and the residents}

The students reported that the staff's use of PPE was also a big problem for the elderly, who already had their social contacts drastically reduced and fewer daily activities. The staff were also so busy that they did not have time to talk etc. Students noticed that personal contact between the staff and residents was greatly impaired by the use of PPE and that users often felt distressed: "Social contacts suffered at the expense of everything else. There were also many (residents) who could not even recognise such staff in this equipment at all" (S1).

They detected that PPE had reduced the quality of communication: "There is less contact, even eye contact is worse, you hear worse, while touch in the Tyvek and gloves is not the same as without them..." (S8).

There was a lack of understanding of the situation by people with dementia: "One lady thought she was in jail and was apologising to us all the time" (S10).

One student, who had worked at a nursing home with enough staff, reported they were able to devote enough time to the residents' social contacts.

We took those who were in bed all the time in front of the glass door, to be seen through it, we lifted the bed for them to see, and then we held the phone to their ears so they could talk live to their loved ones. Yeah, we improvised a little. And we also made video calls for them. (S10)

\section{Discussion and conclusion}

We may conclude from our results that the staff and residents in Slovenia's nursing homes encountered similar problems to those described by other researchers abroad - a shortage of staff, poor quality PPE, the lack of clear guidelines for work, and deficient knowledge among the staff (Szczerbinska, 2020, Thompson et al., 2020). A lack of PPE can prove to be very dangerous - staff is consequently under greater psychological pressure and, when PPE is reused, life-threatening mistakes can occur very quickly. Good quality PPE is also es- 
sential for safe work. The students also noticed the lack of checking of staff's consistency at work, reduced personal contact between staff and residents due to the PPE, lack of knowledge regarding proper PPE use as well as virus properties. Based on a quote from a student who concluded that the changing guidelines mean it probably does not matter how gloves are used, we can underscore the importance of clear guidelines for ensuring awareness of the value of certain measures. Another student report shows that external checking of PPE use and compliance with the measures can make staff more consistent in those areas. Better knowledge about the virus and PPE use can also lead to greater consistency. This also affects staff's perception of the seriousness of the situation. The findings allow us to confirm that staff shortages impact the work and well-being of staff as well as the residents' quality of life. Enough staff means less workload and less exhaustion for staff, and this positively affects the quality of work and number of mistakes made. When there are enough staff, it is also easier to organise proper social activities and contacts for residents, which considerably impact the residents' health and well-being (Simard and Volicer, 2020). Shortcomings that surfaced during the COVID-19 epidemic should be pointed out, along with errors in the work process. Further research on these issues in our environment could assist our nursing home systems in being better prepared for potential, similar situations. Our findings may serve as a starting point for that. They could also serve as a starting point for recommendations for better and safer working and living in these facilities for both staff and residents.

\section{References}

BHAGAVATHUlA, A.S., ALDHALEEI, W.A., RAHMANI, J., MAHABADI, M.A. and BANDARI, DK., 2020. Knowledge and Perceptions of COVID-19 Among Health Care Workers: Cross-Sectional Study. Public Health and Surveillance, vol. 6, no. 2, pp. e1916o. Available from: https://publichealth.jmir.org/2020/2/e1916o/.

LOFTI, M., HAMBLIN, M.R. and REZAEI, N., 2020. COVID-19: Transmission, prevention, and potential therapeutic opportunities. Clinica Chimica Acta, no. 508, pp. 254-266. Available from: https://pubmed.ncbi.nlm. nih.gov/32474009/.

NIJZ (2020). Priporočila za preprečevanje in zajezitev okužb z virusom SARSCOV-2v socialnovarstvenih zavodih. [online]. [viewed 21 November 2020]. Available from: https://www.nijz.si/sites/www.nijz.si/files/uploaded/priporocila-za-preprecevanje-in-zajezitev-okuzb-z-virusom-sars-cov-2-16.10.2020.pdf.

SIMARD, J. and VOLICER, L., (2020). Loneliness and isolation in long-term care and the COVID-19 pandemic. JAMDA, vol. 2020, no. 21, pp. $966 e 967$. Available from: https://doi.org/10.1016/j.jamda.2020.05.006. 
SZCZERBIŃSKA, K., (2020). Could we have done better with COVID-19 in nursing homes? European geriatric medicine, no. 11, vol. 4. pp. 639-43. Available from: https://link.springer.com/article/10.1007/s41999-02000362-7.

THOMPSON, D.C., BARBU, M.G., BEIU, C., POPA, L.G., MIHAI, M. M., BERTEANU, M., POPESCU M. N., 2020. The Impact of COVID-19 Pandemic on Long-Term Care Facilities Worldwide: An Overview on International Issues. Biomed research international, vol. 2020, no. 4, pp. 8870249 . Available from: https://www.hindawi.com/journals/bmri/2020/8870249/.

UKOM (2020). Država v domove starejših občanov ni vlagala, zato je veliko smrti stanovalcev. [online]. [viewed 17 February 2020]. Available from: https://www.gov.si/novice/2021-01-11-drzava-v-domove-starejsih-obcanov-ni-vlagala-zato-je-veliko-smrti-stanovalcev/ <17. 2. 2021 $\rangle$.

WHITE, E. M., WETLE, T. F., REDDY, A. and BAIER, R.R., 2020. Front-line nursing home staff experiences during the COVID-19 pandemic. Journal of the american medical directors association, vol. 22, no.1, pp. 199-203. Available from: https://pubmed.ncbi.nlm.nih.gov/33321076/.

ZBORNICA-ZVEZA (2020 ). Kdo bo skrbel za paciente, ko medicinskih sester ne bo več? [online]. [viewed 3 January 2020]. Available from: https:// www.zbornica-zveza.si/clanek/kdo-bo-skrbel-za-paciente-ko-medicinskih-sester-ne-bo-vec/. 